\title{
Lattice gas model for company profit: cooperative relation between contractors and subcontractors
}

\author{
Ayako Morishita, Yasuo Tateoka and Kei-ichi Tainaka \\ Graduate School of Science and Technology, Shizuoka University, \\ 3-5-1 Johoku, Hamamatsu, 432-8561, Japan \\ Email: narunaru.g@gmail.com
}

\begin{abstract}
In Japan, there are many long-lived companies which survive more than 200 years. Such companies typically use a cooperative strategy: win-win interactions with other companies. It is very rare for them to dismiss subcontractors. In the present article, we apply ecological theories of population dynamics to illustrate how cooperative management promotes sustainability. We assume three contractors compete in a single market. The scenario examined illustrates that the dismissal of subcontractors is optimal for very short periods, but not optimal in relatively long periods. Hence, the long-term dynamics and perspectives are necessary to know the superiority of cooperative management.
\end{abstract}

Keywords: Company management, cooperation, long-lived companies, contractor and subcontractor, longterm optimality 


\section{INTRODUCTION}

When economic recession occurs, many companies fire subcontractors. The tactic of firing subcontractors is one of defective behaviors (Williamson 1981). Long-lived Japanese corporations take alternative strategy. Based on our knowledge, the dismissal of subcontractors has not happened: they preserve cooperative relationship. So far, the superiority of cooperation to defection has been explained by game theories. A typical example is prisoner's dilemma game. Each player takes one of two options: cooperation and defection. The cooperation is usually optimal for repeated (long-term) game, while the defection is effective for a single (shortterm) game (Axelrod 1997; Nowak 2006). In the present article, we apply conventional method in ecology. The dynamical equation for company profit illustrates that cooperation is more advantageous than defection during a long period.

In Japan, there exist a lot of long-lived companies as listed in Table 1 (Goto 2011). Sustainable management has been studied by many authors (Mehrotra et al. 2013; Zellweger et al. 2012). Its most important feature is giving priority to

Table 1. Number of long-lived companies which survive more than 200 years.

\begin{tabular}{|c|c|c|c|c|c|c|}
\hline Country & Japan & German & UK & France & Italy & Spain \\
\hline Number & 3913 & 1714 & 469 & 390 & 256 & 81 \\
\hline
\end{tabular}

Survey are performed over 59 countries/region (Goto 2011). the consumer's benefit, so that the long-lived companies obey all competition laws (e.g. the prohibition of cartels). Another feature of sustainable management is mutualistic (cooperative) relation (Tateoka and Morishita 2013; Morishita 2014). Here, the mutualistic relation is defined by the win-win interactions; in the relationship between two companies, each company benefits.

The long-lived companies often take altruistic behaviors (Tateoka and Morishita 2013; Morishita 2014; Tateoka 2006). A famous example of altruism has been reported by newspaper (Asahi Newspaper 2011). On March 2011, a powerful earthquake occurred and a large "tsunami" attacked the Japanese shore (see Figure 1). In the northern area of Japan, one long-lived company (Suisen Shuzo Co.), which make "sake" (a kind of

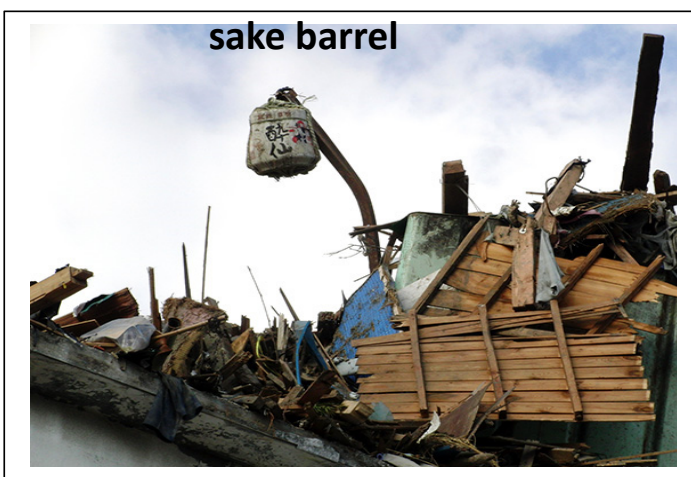

Figure 1. Damage by tsunami (Suisen Shuzo Co., 2015). alcohol), incurred devastating damages by tsunami. However, another sake-maker (Iwate Meijo Co.) saved the company by means of a substantial financial aid. The owner of Iwate Meijo explained the reason for support as follows: "A good rival is necessary for fair competition. Monopoly is a tragedy for consumers". The mutualistic relation for long-lived companies is slightly different from reciprocal relation, because the former contains altruism (Tainaka and Itoh 2002; Yokoi et al. 2014). In Japan, the cooperation is maintained by altruistic behaviors.
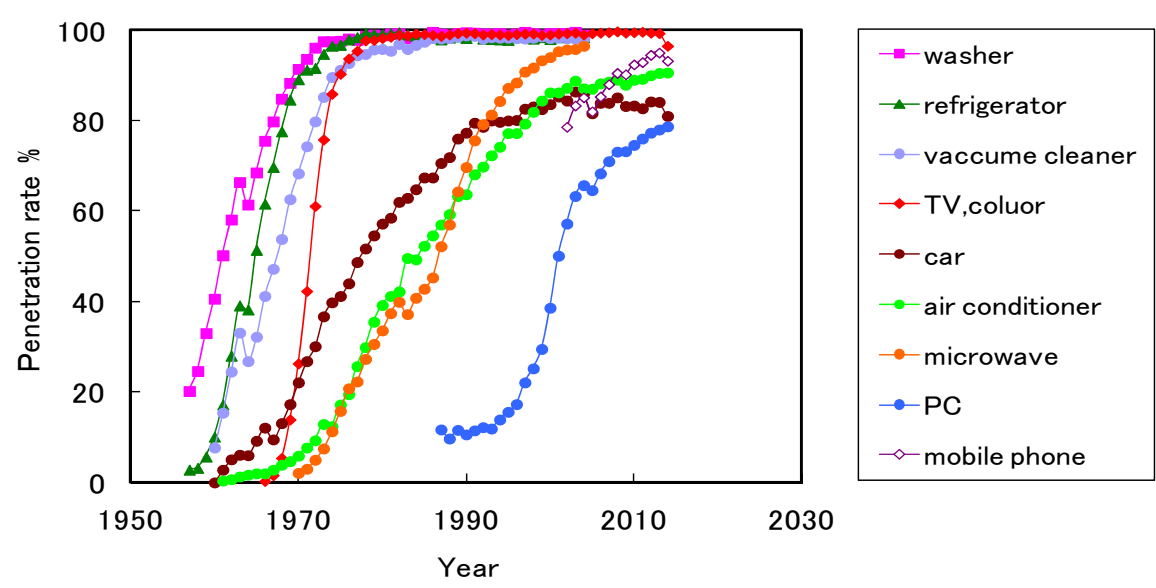

Figure 2. Growth limits for various markets in Japan. The vertical axis means the penetration rates in arbitrary units. The data are based on the survey by Cabinet office in Japanese Government (2014). 
We apply conventional theories in ecology. Since the works of Lotka and Volterra, the population dynamics have been studied extensively (Lotka 1920; Hofbauer and Sigmund 1988; Gurney and Nisbet 1998). It is well known that the Lotka-Volterra equations are the most popular dynamical models in ecosystems. However, they often fail to describe the population dynamics of mutualistic (win-win) relations: the population sizes of species increase infinitely under certain conditions. Recently, Iwata et al. (2011) have applied a lattice gas model; the divergence never occurs in their model, since the total population size (total cells of lattice) is limited. The lattice gas model may be applicable to economic activities, because the economic growth has faced on the limitations in most cases (see Figure 2).

\section{MODEL}

We consider a market where $n$ companies sell the similar product $(n=3)$, and imagine a lattice composed of $L$ cells (see Figure 3). A cell has a unit profit $u$. Thus the total profit $(L u)$ corresponds to the growth limit. Each cell is either occupation $(\mathrm{X} j)$ by company $j$ or no occupation $(\mathrm{O})$. When a company $j$ occupies $N_{j}$ cells $(j=1,2,3)$, the company achieves a profit $u N_{j}$ or density (market share) $x_{j}$, where the density is defined by $x_{j}=N_{j} / L$. The growth process of company $j$ can be represented by

$$
\mathrm{X}_{j}+\mathrm{O} \rightarrow \mathrm{X}_{j}+\mathrm{X}_{j} \quad\left(\text { rate } G_{j}\right)
$$

This reaction means that the increment of profit is proportional to both densities of profit and empty. In contrast, the decreasing process is expressed by

$$
\mathrm{X}_{j} \rightarrow \mathrm{O} \quad\left(\text { rate } d_{j}\right)
$$

The parameter $G_{j}$ and $d_{j}$ are the growth and decreasing rates

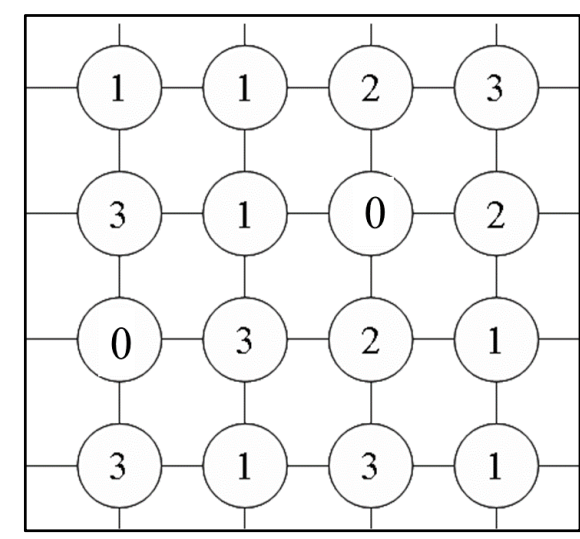

Figure 3. Lattice gas model. The cell indicated by numeral $j$ is $\mathrm{X} j$ which means the occupation cell by contractor $j(j=1,2,3)$, and 0 is the empty cell $(\mathrm{O})$. The empty cell is introduced to prohibit the divergence of profits.

of company $j$, respectively. We assume the rate $G_{j}$ is affected by the other company $k(k \neq j)$

$$
G_{j}=r_{j}+\sum_{k} e_{j k} x_{k}
$$

where $r_{j}$ is rising (intrinsic productivity) rate, and $e_{j k}$ is mutualistic rate. If $e_{j k}$ is positive (negative), the company $k$ give merit (damage) to company $j$.

Simulation method is carried out as follows (Iwata et al. 2011):

1) Initially, we distribute three companies on the lattice (Figure 3).

2) The reactions (1) are performed in the following two steps:

i) Reaction (1a). Two cells are chosen randomly and independently. If chosen sites are $\mathrm{X} j$ and $\mathrm{O}$, then the site $\mathrm{O}$ will become $\mathrm{X}_{j}$ by the rate $G_{j}$ defined by equation (2).

ii) Reaction (1b). Choose one cell randomly; if the cell is $\mathrm{X} j$, it will become $\mathrm{O}$ by the rate $d_{j}$.

3) We repeat above steps i) and ii) until the system reaches a stationary state.

It is emphasized that the reaction (1a) occurs between any pair of cells. Hence, the lattice gas model has no spatial meaning.

If the lattice size $L$ is sufficiently large, the dynamics can be represented by rate equations:

$$
\frac{d x_{j}}{d t}=\left(r_{j}+\sum_{k} e_{j k} x_{k}\right) x_{j}\left(1-\sum_{k} x_{k}\right)-d_{j} x_{j}
$$


where $\left(1-\sum x_{k}\right)$ is the density of empty (cell 0 ). This basic equation always satisfies $1>\sum x_{j}$. Namely, the total profit of all companies never exceeds the growth limit. If economic innovation (recession) occurs, the value of $L$ increases (decreases). The density of company $j$ at equilibrium are never changed, unless the parameter values are altered. Note the profit depends on $L$, because the profit $P_{j}$ of company $j$ is given by

$$
P_{j}=x_{j} L u \text {. }
$$

If the system contains only one company, then equation (3) becomes the logistic growth:

$$
d x / d t=R x(1-x / K),
$$

where $R=r-d$ and $K=1-d / r$. Equation (5) is known to show a sigmoid curve (Gurney and Nisbet 1998).

\section{SIMULATION RESULTS}

\subsection{Cooperation Promotes Coexistence}

From equation (3), the equilibrium (steady-state) densities can be solved analytically. However, the solutions are too complicated. For this reason, we carry out numerical simulations under several scenarios. First, we consider the case that mutual interaction is neglected $\left(e_{j k}=0\right)$. In this case, only competition between companies occurs: companies compete to get the empty cell (O). Figure 4(a) illustrates typical dynamics of density $x_{j}$. It is found from this figure that only a single companies survive. The winner is the company that has largest value of ratio $\left(r_{j} / d_{j}\right)$. When $e_{j k}<0$, the competition becomes much severe; only strongest company survives. Next, we consider the case $e_{j k}>0$, because we mainly deal with long-lived companies [Figure 4(b)]. By the presence of cooperative relations $\left(e_{j k}>0\right)$, all companies are found to coexist.

(a)

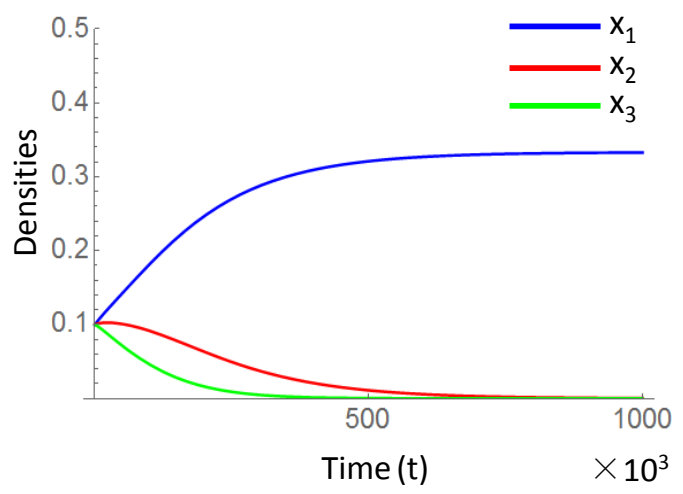

(b)

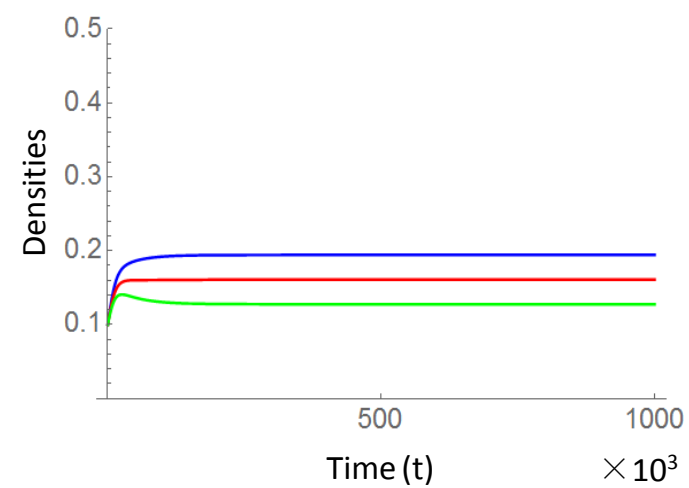

Figure 4. Typical results in a three-company system. The densities (market shares) of individual companies are illustrated, where growth rates are set $r_{1}=0.0030, r_{2}=0.0029, r_{3}=0.0028$, and $d_{j}=0.002$ for any company. (a) Case of no cooperation $\left(e_{j k}=0\right)$. (b) Case of cooperative interactions $\left(e_{j k}=0.003\right)$.

\subsection{Scenario Analysis of Recession: No Dismissal}

Simulations are carried out under a recession. We consider three contractors 1, 2 and 3 compete in a single market; they coexist with mutual cooperation. Initial condition is set to be the stationary state in Figure 4(b), where the density of empty cell is about 0.5 . Before a recession, we put the growth limit (number of total cells) 
is $L_{0}$. At $t=t_{1}$, a recession occurs; $L_{0}$ is decreased. In this paper, empty cells suddenly disappear; the density of empty is decreased from 0.5 to 0.25 at $t=t_{1}$.

First, we assume non-dismissing scenario: no contractor dismisses subcontractors. In Figure 5, the dynamics are illustrated $\left(t_{1}=100\right)$, where (a) and (b) denote densities and profits, respectively. The densities $x_{j}$ are calculated by basic equation (3). Just after recession, the density of each company jump up about $50 \%$, because the density of empty cells suddenly decreases $50 \%$ for $t \geq 100$. In contrast, the profits are continuous at $t=100$, since the profit of each company (number of occupation cells) is unchanged just before and after $t=100$. The profits are obtained by equation (4). For $t \rightarrow \infty$, the densities reach the previous values; thus the steady-state profit of each company at final stage decreases $50 \%$ compared to the previous values.

(a) Densities

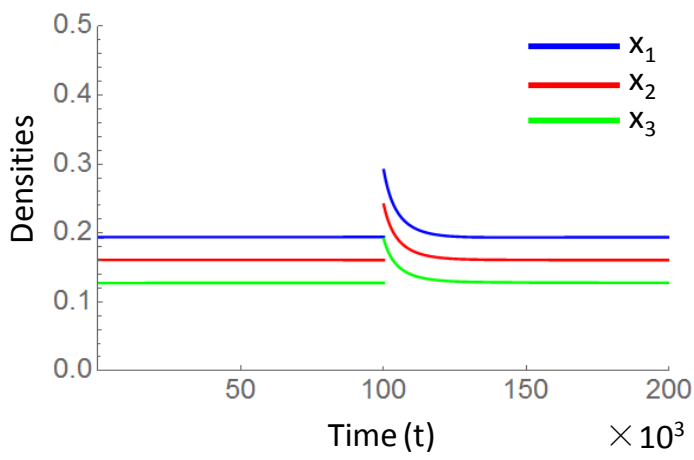

(b) Profits

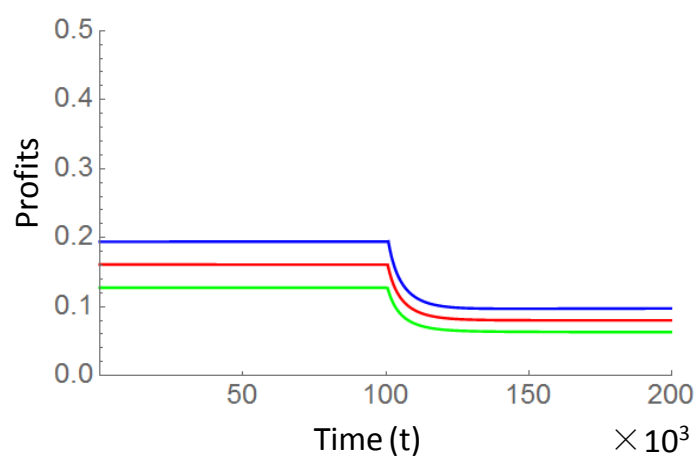

Figure 5. Results of scenario analysis for recession: non-dismissing case. (a) Densities $x_{j}$, (b) profits $\left(P_{j}\right)$. A recession occurs for $t \geq 100$. The value of profit is divided by $u L_{0}$. The parameter values are the same as in Figure 4(b). At $t=100$, empty cells suddenly disappear; the density of empty cell changes from 0.5 to 0.25 .

\subsection{Effect of Dismissing}

Next, we consider the case that only contractor 1 dismisses subcontractors for $t \geq 100$. The dismissal brings about two effects on contractor 1 :

i) the payment to subcontractors can be reduced

ii) the rising (productivity) rate $r_{1}$ is decreased

The factors i) and ii) are the merit and demerit by dismissing, respectively. By the factor i), the profit ( $\left.P_{1}\right)$ of company 1 is increased by

$$
P_{1}=\left(x_{1}+\Delta p\right) L u
$$

where $\Delta p$ is the merit (increment) by dismissing. On the other hand, the profits of non-dismissing companies are represented by equation (4). The reasons why $r_{1}$ is decreased are discussed later. Figure 6 display the same figure as Figure 5, but both effects i) and ii) due to dismissing are included. In Figure 6(a), the value of $r_{1}$ is decreased $\left(r_{1}=0.30 \rightarrow 0.27\right)$. For $t \rightarrow \infty$, the density $x_{1}$ is lower than both $x_{2}$ and $x_{3}$. In Figure 6(b), the profit curve of contractor 1 is not continuous at $t=t_{1}$. This is because the contractor 1 gains the merit $(\Delta p)$ by the dismissing for $t \geq t_{1}$. We compare the profits of contractor 1 in two cases whether contractor 1 dismisses subcontractors or not [Figure 5(b) and Figure 6(b)]. Just after the dismissal, the profit of contractor 1 increases, but later it decreases. Such a reversal of profit occurs at $t \approx 138$. Hence, Figure 6 indicates the disadvantage of dismissal during a long period $(t>138)$. It should be emphasized that non-dismissing contractors 
(companies 2 and 3) indirectly gain merits by the dismissal of contractor 1: the profits of non-dismissing contractors become higher compared to non-dismissing case [see Figure 5(b)].

(a) Densities

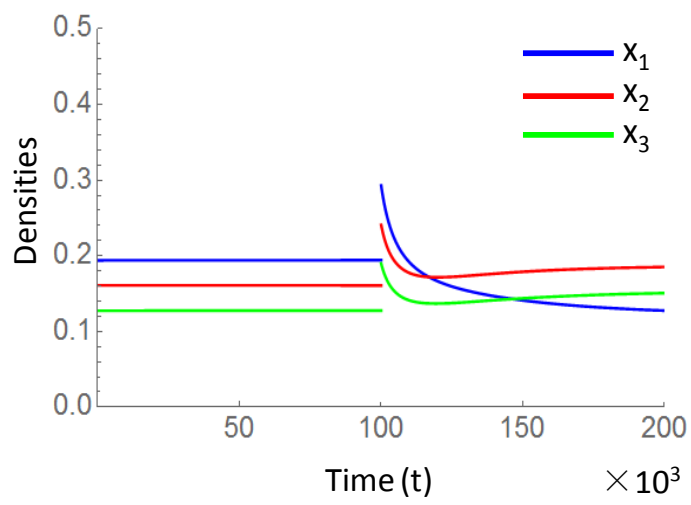

(b) Profits

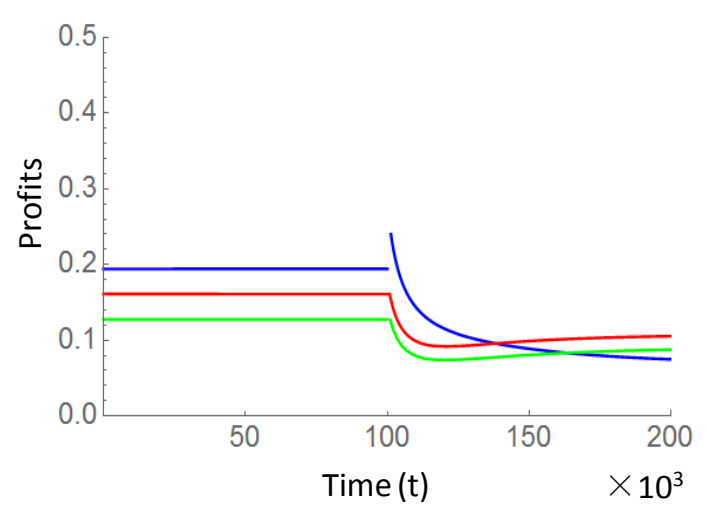

Figure 6. Same as Figure 5, but contractor 1 (blue curve) dismisses subcontractors. For $t \geq 100$, the rising rate of contractor 1 is decreased from $r_{1}=0.0030$ to $r_{1}=0.0027$; in contract, the profit of contractor 1 is increased $(\Delta p=0.05)$.

\section{DISCUSSION AND CONCLUSIONS}

We have developed a dynamic model for long-lived companies. Sustainable management in Japan has a distinct feature: companies engage in mutualistic (win-win) interactions even with competing companies. We explore the scenario analysis for recession. Profits are calculated in two cases; (A) no contractor dismisses subcontractors (see Figure 5), and (B) only contractor 1 dismisses subcontractors (see Figure 6). We compare Figures $5(\mathrm{~b})$ and $6(\mathrm{~b})$, and find that the termination of subcontractor is advantageous in short period ( $100<t<138)$, but it is disadvantageous in long period $(t>138)$. Moreover, these figures indicate that nondismissing contractors ( 2 and 3 ) gains merits by the dismissal of contractor 1 . This merit comes from the competition in a market. Since three companies compete to get the empty cell (O), the decrease of $r_{1}$ indirectly gives the merits to both companies 2 and 3 .

Parameter sensitivity is discussed. The values of parameters sensitively effect on results. If the gain $(\Delta p)$ by dismissal is too large, or if the decrease of rising (productivity) rate $r_{1}$ is too small, then the termination of subcontractor becomes advantageous. It is noted that the dismissal may be necessary, if the risk of bankruptcy is too high. The decrease of $r_{1}$ is due to the decrease of ability. As the cause of such decrease, we consider two factors: i) the termination of subcontractors, and ii) decrease of cooperative mind. The cooperative mindset affects on the productivity of company (Tateoka 2006).

Some simplifications in our model are discussed. First, we carry out simulation of a recession. In the modeling of recession, the growth limit $L$ is suddenly decreased. Such a shock could also be attributed to, say, a natural disaster. In the present article, only empty cells are removed. We can change such a removal method; an example is the removal of both empty and occupation cells. Second, we discuss cooperative parameters $e_{j k}$. In real case, each company closely related to other companies; companies help with each other. Examples are technology diffusion, employee mobility between companies. Our model may be applicable for various types of company helpings.

In summary, the merit and demerit of non-dismissing are listed in Table 2. The easiest and quickest methods for an economic recession is the termination of subcontractors. In fact, difference between Figures 5 and 6 illustrate that the termination is advantageous for a while $(t \leq 138)$. However, later $(t>138)$, it is disadvantageous due to the decrease of $r_{1}$. It is noted that a contractor unavoidably dismisses subcontractors; if the risk of bankruptcy is too high, then the dismissal may be necessary. Moreover we discuss the future effect 
by dismissing. Business activity oscillates up and down. When the activity becomes high (business boom), dismissing companies require new subcontractors. They need extra money (higher than $\Delta p$ ) for the contract. Hence the non-dismissing company is advantageous for business boom. Moreover, "providential wind" may come for non-dismissing company: the providential wind denotes many supports from various parties (people). When the company of cooperative management faces a risk of bankruptcy, many people save the company by various supports (e.g. Suisen Shuzo Co. at tsunami: see Figure 1).

Table 2. Merit and demerit for non-dismissing contractors.

\begin{tabular}{|l|l|l|}
\hline \multicolumn{1}{|c|}{ Period } & \multicolumn{1}{|c|}{ Merit } & \multicolumn{1}{c|}{ Demerit } \\
\hline $\begin{array}{l}\text { Very short period } \\
(100<t<138)\end{array}$ & None & Payment to subcontractor \\
\hline $\begin{array}{l}\text { Relatively long period } \\
(t>138)\end{array}$ & $\begin{array}{l}\text { Increase of cooperative mind } \\
\text { Maintenance of high value of } r_{j}\end{array}$ & Risk of bankruptcy \\
\hline $\begin{array}{l}\text { Future effect } \\
\text { (No simulation) }\end{array}$ & $\begin{array}{l}\text { Advantageous for business boom } \\
\text { "Providential wind" }\end{array}$ & None \\
\hline
\end{tabular}

\section{REFERENCES}

Asahi Newspaper (2011). https://ajw.asahi.com/article/0311disaster/recovery/AJ201108126138. Accessed 23 September 2014.

Axelrod, R. (1997). The complexity of cooperation: Agent-based models of competition and collaboration. Basic Books, New York.

Cabinet office in the Japanese government. http://www.esri.cao.go.jp/jp/stat/shouhi/shouhi.html. Accessed 23 September, 2014.

Gurney, W.S.C., and Nisbet, R.M. (1998). Ecological Dynamics. Oxford University Press, Oxford.

Goto, T. (2011). International comparison of longevity of firms; from the family business perspectives (in Japanese). National Conference of the Academic Association for Organizational Science, Tokyo, Japan, June 4-5, 271-274.

Hofbauer, J., and Sigmund, K. (1988). The theory of evolution and dynamical systems. Cambridge Univ. Press, Cambridge.

Iwata, S., Kobayashi, K., Higa, S., Yoshimura, J., and Tainaka, K. (2011) A simple population theory for mutualism by the use of lattice gas model. Ecological Modelling, 222 (13), 2042-2048.

Lotka, A.J. (1920). Analytical note on certain rhythmic relations in organic systems. Proc. Natl. Acad. Sci. USA, 6, 410-415.

Mehrotra, V., Morck R., Shim J., and Wiwattanakantang Y. (2013). Adoptive expectations: Rising sons in Japanese family firms. Journal of Financial Economics, 108 (3), 840-854.

Morishita, A. (2014) Mutualistic interactions in long-lived firms (in Japanese). East Asia scientific management Conference, Tokyo, Japan, September 12-14, 114-117.

Nowak, M.A. (2006). Five rules for the evolution of cooperation. Science, 314, 1560-1563.

Suisen Shuzo Co. http://suisenshuzo.jp/about/history.html. Accessed 23 September, 2015.

Tainaka, K., and Itoh, Y. (2002). Patch dynamics based on Prisoner's Dilemma game: Superiority of Golden Rule. Ecological Modelling, 150, 295-307.

Tateoka, Y. (2006). Altruism driven economy (in Japanese). Shin-Yo-Sha, Tokyo.

Tateoka, Y., and Morishita, A. (2013). Towards inner-relation driven management: from the perspective of organization reformation and sustainability (in Japanese). Journal of Japan Management Diagnosis Association, 13, 88-93.

Williamson, O.E. (1981). The economics of organization: The transaction cost approach. The American Journal of Sociology, 87, 548-577.

Yokoi, H., Uehara, T., Sakata, T., Naito, H., Morita, S., and Tainaka, K. (2014). Evolution of altruism in spatial prisoner's dilemma: intra- and inter-cellular interactions. Physica A, 416, 361-370.

Zellweger, T.M., Nason, R.S., and Nordqvist, M. (2012). From longevity of firms to transgenerational entrepreneurship of families introducing family entrepreneurial orientation. Family Business Review, 25 (2), 136-155. 